\title{
Laboratório de Estudos Cognitivos: percursos de pesquisa, formação e criação
}

\section{Laboratory of Cognitive Studies: paths of research, training and creation}

\section{Léa da Cruz Fagundes}

Universidade Federal do Rio Grande do Sul

Rosane Aragón

Universidade Federal do Rio Grande do Sul

\section{Marcus Vinicius de Azevedo Basso}

Universidade Federal do Rio Grande do Sul

Cleci Maraschin

Universidade Federal do Rio Grande do Sul

\begin{abstract}
Resumo: Durante sua trajetória, o Laboratório de Estudos Cognitivos - LEC desenvolveu uma multiplicidade de projetos que envolveram pesquisa, formação, criação de plataformas virtuais interativas e objetos digitais de aprendizagem, como também, manteve uma presença importante e, mesmo pioneira, na formulação e desenvolvimento de políticas regionais, nacionais e internacionais de inclusão digital. Neste artigo, escolhemos focar nos desdobramentos dos três primeiros aspectos mencionados, salientando as articulações entre pesquisa, formação e desenvolvimento. Com essa escolha, relatamos algumas das principais contribuições do Laboratório, embora conscientes de que esse mapeamento representa seu trabalho apenas parcialmente.
\end{abstract}

Palavras-chave: Laboratório de Estudos Cognitivos. Pesquisa cognitiva. Formação de professores. Ferramentas digitais de aprendizagem.

Abstract: During its history, the Laboratory of Cognitive Studies (LEC) developed a multiplicity of projects that involved research, teacher education, creation of interactive virtual platforms and digital learning objects, as well as maintained an important and even pioneering presence in the formulation and development of regional, national and international digital inclusion policies. In this article, we chose to focus on the development of the first three aspects mentioned, highlighting the links between research, training and development. With this choice, we report 
some of the main contributions of the Laboratory, although aware that this mapping only partially represents its contributions.

Keywords: Laboratory of Cognitive Studies. Cognitive research. Teacher education. Digital learning tools.

FAGUNDES, LÉA DA CRUZ et al. Laboratório de Estudos Cognitivos: percursos de pesquisa, formação e criação. Informática na Educação: teoria \& prática, Porto Alegre, v. 22, n. 2, p. 242-257, maio/ago. 2019.

\section{Introdução}

Idealizado e coordenado pela professora Léa da Cruz Fagundes, o Laboratório de Estudos Cognitivos (LEC/UFRGS) foi fundado em 1973, como Grupo de Estudos Cognitivos e, desde 1982, foi reestruturado como Laboratório. Seu nascimento deu-se partir de cursos e de pesquisas sobre cognição e epistemologia genética, ministrados e supervisionados pelo médico pesquisador argentino Antonio Maria Battro, que havia estudado com Jean Piaget no Centro Internacional de Epistemologia Genética da Universidade de Genebra. Desde seu início, o Laboratório de Estudos Cognitivos manteve uma característica interdisciplinar, integrando participantes de diferentes áreas do conhecimento, incluindo estudantes de diversos níveis acadêmicos e firmando parcerias com diversas instituições da sociedade.

Retomar aspectos da trajetória do LEC contribui para preservar a memória dos processos de construção coletiva que colaboraram significativamente para projetar o campo da informática na educação na UFRGS e subsidiaram sua participação na formulação e desenvolvimento de políticas regionais, nacionais e internacionais de inclusão digital. Neste artigo, escolhemos focar nas articulações entre pesquisa, formação e desenvolvimento. Com essa escolha, relatamos algumas das principais contribuições do Laboratório, embora conscientes de que esse mapeamento representa apenas parcialmente o trabalho desenvolvido.

\section{Em busca de novos recursos para aprender}

A pergunta pela cognição e pelos modos como se aprende acompanha a trajetória de trabalho do LEC, embora sua formulação tenha se modificado no transcurso das experiências de pesquisa, de ensino e de extensão. Desde o início, a cognição e a aprendizagem são estudadas considerando as contingências nas quais se efetuam. Essa conexão entre cognição/aprendizagem-em-contexto possibilitou a inclusão nos estudos das tecnologias digitais, fornecendo um conjunto de resultados valiosos para a psicologia cognitiva, para a educação e para a formação de professores.

A experiência da Professora Léa com a educação básica Ihe possibilitou problematizar que o modo como a escola ensinava encontrava-se afastado dos contextos de experiência dos 
estudantes, principalmente daqueles oriundos de estratos socioeconômicos desfavorecidos, o que explicaria sua maior dificuldade com os conteúdos escolares. Mas a solução não estaria no fato de que esses estudantes devessem permanecer somente com os recursos culturais de suas comunidades. A aposta sempre foi a de desafiar a escola a proporcionar acesso a diferentes objetos culturais embora, muitas vezes, nem mesmo os professores a eles tivessem acesso. É nesse intervalo - entre a experiência concreta de vida dos estudantes e de seus professores e 0 acesso a diferentes objetos culturais - que o LEC desenvolveu grande parte de suas pesquisas. A proposta é que "Todos são capazes de aprender" e que "Um professor pode ensinar o que ainda não sabe, ao se dispor a aprender junto com seu aluno". Com essas premissas, os estudos possibilitaram construir resultados importantes para a inclusão da instituição escolar na cultura digital.

Alguns apontamentos desse percurso merecem destaque. No final dos anos de 1980, pesquisadores do campo cognitivo estavam interessados em estudar os efeitos, principalmente para o desenvolvimento cognitivo e para a aprendizagem, da interação com o computador e com as linguagens de programação. Estimulada por Antonio Battro, a equipe do LEC passou a promover esforços para direcionar suas pesquisas considerando esse objeto técnico e seus efeitos na cognição e na aprendizagem.

Ao acompanhar, no Hospital Del Niño, em Buenos Aires, o trabalho do Prof. Battro, no qual crianças interagiam com computadores, a Professora Léa lançou o desafio aos pesquisadores do LEC de desenvolver essa temática de pesquisa no Brasil. Passou a buscar um computador, mas esbarrou nas proibições impostas pelo governo militar, quando não era permitida a importação de equipamentos digitais, dado que informática era considerada uma questão de segurança nacional. Nem mesmo a negativa que recebeu da Secretaria Especial de Informática do Governo Militar a fez esmorecer. Foi em 1979, com o Engenheiro José Medero, colega do Instituto de Física, que a Professora Léa conseguiu construir o primeiro computador para uso em pesquisas no LEC. Desde então, o LEC vem investigando os processos de desenvolvimento cognitivo de estudantes e de professores em diferentes situações de aprendizagem na interação com tecnologias digitais.

Naquele momento, as parcerias de pesquisa foram ampliadas, passando a incluir pesquisadores do MIT (Massachusetts Institute of Technology/USA) e da Unicamp. Mais especificamente, houve colaboração com o Professor Seymour Papert e com o Professor José Armando Valente. Seymour Papert desenvolveu a Linguagem LOGO de programação, possibilitando que crianças ainda não alfabetizadas e estudantes percebidos como tendo dificuldades de aprendizagem pudessem programar um computador, mesmo conhecendo poucos comandos. Uma série de estudos, teses e dissertações foram realizadas no contexto dessa parceria, com o Professor Papert visitando o LEC em duas ocasiões para discutir os resultados encontrados. Dentre os estudos, destacamos: o funcionamento cognitivo da criança em interação 
com o computador - sobre psicogênese (FAGUNDES, 1986); conhecimento sobre competência e performance linguística (AXT, 1986, 1988 e 1989).

Em 1984, o LEC passou a compor, juntamente com outras universidades nacionais, o projeto Educom: uma das primeiras políticas públicas que visava buscar subsídios para a integração de tecnologias na educação. A partir daí, o LEC firmou-se como um centro de excelência em pesquisa na área, constituindo um espaço de referência a proposições de políticas públicas no campo da inclusão digital. As pesquisas desenvolvidas deram suporte ao trabalho de intervenção e de formação em diferentes níveis da educação, voltados a uma inclusão digital que qualifica a aprendizagem em diferentes sentidos, seja ela dos estudantes, dos professores e de mestrandos e doutorandos. Os estudos se direcionaram a indagar: quais os efeitos desse [então] novo objeto técnico para a cognição? Ele se tornaria uma ferramenta para pensar-com? Modificaria os processos de aprendizagem? O que aconteceria se estudantes considerados como tendo problemas de aprendizagem aprendessem a programar o computador? Poderia essa nova tecnologia vir ao auxílio nos processos de alfabetização? Com essas questões no horizonte, uma série de pesquisas iniciou a ser realizada. Alguns resultados podem ser encontrados discutindo modelos para o processo de alfabetização (MARASCHIN, 1986; NEVADO, 1988); bem como sobre aprendizagem do número (BÚRIGO e BASSO, 1988).

$\mathrm{Na}$ época, um dos objetivos foi investigar as hipóteses de leitura e de escrita de crianças em processo de alfabetização que utilizavam, como ferramenta interativa, a linguagem LOGO de programação. Tal interesse se justificava pela grande incidência de fracasso escolar nas séries iniciais da educação básica. Aliados a essa problemática educacional, surgiram os estudos de Emília Ferreiro, uma pesquisadora piagetiana argentina que tratou a alfabetização como um processo lógico de conceituação, cunhando a expressão "psicogênese da alfabetização". Desse modo, o interesse era avaliar se a atividade de programação na Linguagem LOGO, por crianças pré-escolares e estudantes do primeiro ano do ensino fundamental, poderia ser considerada uma boa coadjuvante na psicogênese da alfabetização. Os resultados permitiram observar que a atividade de programação constituía uma nova alfabetização, existindo uma modulação conjunta dos dois processos. Isto é, a atividade de programar possibilitava às crianças testar suas hipóteses em relação à escrita alfabética e numérica, mas também as introduzia na produção de algoritmos para se comunicarem com a máquina, o que configurava outra escrita e outra comunicação. A experiência com essas crianças evidenciou que não havia apenas um processo de alfabetização, mas vários, dependendo das linguagens e dos modos de comunicação utilizados. O resultado mais interessante era que essas alfabetizações não competiam entre si como à época pensavam alguns educadores. A crença pregressa era de que uma criança não alfabetizada que aprendesse a programar um computador teria mais dificuldades em sua alfabetização alfanumérica, de modo que estes educadores recomendavam o uso de computadores somente após a alfabetização escolar. Ao contrário do que propunham, os resultados das investigações realizadas no LEC mostraram que a alfabetização em uma linguagem de programação ampliava as possibilidades de alfabetização em outras linguagens ao 
oferecer outros contextos de experiência (MARASCHIN, 1989; MARASCHIN e NEVADO, 1991; MARASCHIN, 1992).

Assim, desenvolveu-se a pesquisa "Em busca de novos recursos para a alfabetização", que consistia em acompanhar estudantes de uma escola pública classificados como tendo dificuldades de aprendizagem para avaliar suas estratégias de aprendizagem. Uma turma de estudantes repetentes ou multirrepetentes comparecia semanalmente ao LEC para "ensinar o computador" a realizar alguns procedimentos, principalmente gráficos, utilizando a Linguagem LOGO. O deslocamento de quem não aprende para quem ensina colocava esses estudantes em uma posição inusitada, oportunizando experimentar a si mesmos com outras potências. Além disso, o teste de hipóteses obtido, quando rodavam o programa escrito, Ihes possibilitava uma autoavaliação imediata do que tinham imaginado com aquilo que o computador efetuava. Tal comparação, na maioria das vezes, os desafiava a debugar o programa proposto e seguir tentando. $O$ tempo que permaneciam atentos a determinada atividade teve um incremento logo nas primeiras sessões de programação. O estudo evidenciou também que, após cerca de vinte e cinco sessões de programação, a maioria dos estudantes modificaram seus modos de aprender na escola, surpreendendo a si mesmos e a seus professores. Tais resultados animaram a equipe do LEC a seguir realizando uma série de estudos com crianças e jovens em diferentes condições de desenvolvimento, incluindo, além dos repetentes e os com diagnósticos de dificuldades de aprendizagem, crianças com deficiência mental e psicose. Pois, se existiam várias alfabetizações e se a atividade de programação fornecia ferramentas para pensar-com, haveria também diferentes acoplamentos para ativar os processos de aprendizagem. Assim, essas crianças e jovens poderiam ter sucesso em outras experiências, uma vez que outras configurações interativas Ihes fossem oportunizadas. De fato, isso aconteceu, e uma edição especial da Revista Psicologia: Reflexão e Crítica, de 1992, foi dedicada aos resultados dessas pesquisas (MARASCHIN e FAGUNDES, 1992; MARASCHIN e NEVADO, 1992).

Os estudos possibilitaram ainda outra análise: o efeito de aprendizagem nos participantes não decorria somente da programação em LOGO, mas a programação aliada a uma proposta de intervenção que nomeamos de "Clube LOGO". O Clube LOGO consistia em um espaço de encontro no qual os participantes eram convidados a programar o computador para que ele realizasse procedimentos de seu interesse, como gráficos ou pequenos jogos com palavras e números. Acompanhados por um "facilitador" que fazia intervenções a partir dos princípios do método clínico crítico: perguntas de exploração, de justificação e de contra-argumentação. Os participantes eram considerados pequenos cientistas que necessitavam explorar, justificar e argumentar suas hipóteses e testá-las observando se o computador realizava ou não o programa da forma como tinham imaginado. Esse formato operava como potencializador da aprendizagem, pois além do Clube acontecer nas dependências da universidade, o que dava credibilidade à performance dos pequenos cientistas -, os participantes trocavam entre si muitas ideias e dicas de como programar. Assim, as pesquisas revelaram que além do computador e da programação, outro fator importante na obtenção de tais resultados era oriundo da própria metodologia da pesquisa: o método clínico e suas intervenções. A compreensão de que o desenvolvimento 
cognitivo e seus efeitos na aprendizagem ocorriam, não somente com o uso do computador e da programação, mas também pelo modo como esse uso se produzia, levou a uma série de pesquisas que culminaram com a proposição dos Projetos de Aprendizagem e da criação de uma Política de Formação, sobre o que trataremos a seguir.

Além da temática da alfabetização e aprendizagem, outras pesquisas trouxeram subsídios para os desenvolvimentos de produtos, para a pesquisa e para a formação docente. Entre elas citamos: sobre a expressão gráfico plástica (BIAZUS, 1991); em Educação Especial (COSTA, CORTE REAL e FAGUNDES, 1990), sobre o tratamento do afeto (KESSLER, 1991 e PEDÓ, 1992), para explicar e ativar os mecanismos de abstração reflexiva, de generalização construtiva e metacognição no processo de aprendizagem (FAGUNDES e NEVADO, 1991), para a formação de professores e de psicólogos (FAGUNDES e PETRY, 1992).

\section{Em busca de novas metodologias para a formação de professores. Uma história que começou com um computador e muitas ideias transformadoras}

O desdobramento da pesquisa, baseada em uma abordagem construtivista, possibilitou constatar que somente a inclusão de artefatos digitais nas práticas de ensino e aprendizagem não garantia uma mudança significativa. Fazia-se necessário a reconstrução de modelos de metodologia de ensino e de formação de professores. Além disso, as tecnologias digitais constituíam uma oportunidade para problematizar práticas habituais de formação. Tal constatação deu ensejo a uma política de formação em dois níveis distintos, porém indissociáveis:

1) formação interdisciplinar de pesquisadores, e

2) formação de professores tanto para testar e disseminar o conhecimento construído na pesquisa como para construir novos conhecimentos, retroalimentando a própria pesquisa.

Em 1991, o LEC passou a investigar as possibilidades de implantação de redes informáticas para comunicação a distância capazes de possibilitar uma educação/formação não presencial. Como na época, o alto custo do acesso aos serviços de teleinformática tornavam impossível sua utilização para fins educacionais, o LEC buscou como solução instalar uma rede de comunicação usando a tecnologia "Packet Radio"; via frequência de rádio amador. Com auxílio da OEA, obteve financiamento para o desenvolvimento de uma pesquisa envolvendo crianças e adolescentes surdos. Através desse estudo, foi possível instalar as primeiras estações da rede que passaram a servir, também, a comunicação de ouvintes. Em outubro de 1991 foram iniciadas transmissões entre escolas públicas de Porto Alegre e Novo Hamburgo (RS) e, em 1992, escolas de outros municípios do Rio Grande do Sul iniciaram sua participação. A rede assim constituída, além de 
aumentar a abrangência do trabalho, suscitou outras problemáticas e o ingresso do LEC na educação a distância.

Em 1994, o LEC realizou o seu primeiro curso a distância usando a tecnologia da rede telemática: o Curso de Pós-Graduação lato-sensu, denominado Especialização em Psicologia do Desenvolvimento Cognitivo aplicada à Educação em Ambientes Informáticos que foi realizado mediante um intercâmbio entre o LEC/UFRGS e Programa de Informática Educativa da Fundação Omar Dengo - Ministério de Educação Pública (PIE/FOD/MEP) da Costa Rica, América Central. Um de seus objetivos foi o de atender a uma das proposições do Banco Internacional de Desenvolvimento (BID) na busca de estabelecer metodologias que possibilitassem avaliar mudanças cognitivas dos estudantes com o uso de tecnologias digitais. Um dos importantes resultados do curso foi a possibilidade de criação de um modelo de formação que propôs incorporar a tecnologia da comunicação em rede ao fazer diário dos professores. Cada professor, em sua escola, realizou projetos de intervenção no modelo de construção autônoma de conhecimento que fora proposto, nessa época, pela filosofia e pelas políticas tanto no PIE/FOD/MEP quanto no PRONINFE/SEMTEC/MEC ${ }^{1}$ para o ensino fundamental.

A partir dessas formações iniciais, com destaque para os Cursos de Especialização em Informática Educativa para professores das redes estadual e municipal de ensino, multiplicadores nos Núcleos de Tecnologia Educacional (NTE) realizados de 1997 até 2000 (PROINFO/MEC²), o LEC consolida sua abordagem teórico-metodológica para a formação de professores. Essa abordagem busca disseminar o conhecimento construído, diferenciando-se do que pode ser caracterizado por um "design pedagógico passivo". Nessa abordagem, busca-se superar a ideia de formação como planejamento central para realizar um atendimento de massa, auxiliando os professores a utilizarem os recursos tecnológicos para enriquecer as ofertas de aprendizagem, nas quais cada aluno, inclusive o professor, é considerado um sujeito ativo e autônomo, em interação com o mundo (COSTA; FAGUNDES; NEVADO, 1998). Uma das formas propostas pelo LEC para alcançar essa intenção são os projetos de aprendizagem. O trabalho de formação com projetos teve início com a formação de professores multiplicadores. Segundo Fagundes et al. (2006, p. 29), "[...] o desenvolvimento de projetos de aprendizagem explora os princípios do construtivismo e dá suporte ao construcionismo - nele, o estudante constrói conhecimento a partir da exploração de uma questão de investigação." Essa questão parte das próprias dúvidas e indagações dos sujeitos, o que se constitui em uma inversão do que normalmente ocorre nas escolas e mesmo nas formações de professores, quando os professores ou formadores definem pelo aluno o que e como ele deve aprender. Conforme Fagundes, Sato e Maçada (1999), quando o aprendiz é desafiado, quando formula questões significativas relacionadas a sua história de vida, abre caminhos para definir de forma autônoma possíveis direções para as suas explorações. As estratégias propostas para dar sustentação aos projetos de aprendizagem possuem um

1 Programa Nacional de Informática Educativa - Secretaria de Educação Média e Tecnológica Ministério da Educação.

2 Programa Nacional de Tecnologia Educacional - Ministério da Educação. 
caráter estruturante, ou seja, buscam apoiar metodologicamente os caminhos trilhados pelos aprendizes. Não há um único caminho, os caminhos são construídos a partir das escolhas e das interações com os pares e com os professores. Nos projetos, o professor trabalha com uma intenção problematizadora, considerando importante perturbar as certezas dos alunos, criar "situações de dúvida", mas também desenvolve uma ação complementar que é a de apoiar as reconstruções. O foco não está na aprendizagem de conteúdos definidos na grade curricular, isso é uma consequência. A prioridade é desenvolver a própria capacidade de continuar aprendendo, o aprender a aprender, que se dá num processo contínuo e majorante de duvidar do que já se sabe (certezas), definir dúvidas coerentes com a questão a ser investigada, organizar formas de buscar e selecionar informações e reconstruí-las em novas certezas e novos problemas.

Nesse período, o LEC propõe a concepção pedagógica para a primeira plataforma virtual de aprendizagem e-Proinfo da Secretaria de Educação a Distância do MEC, a qual foi utilizada por mais de 300 professores de vários estados brasileiros na elaboração de Projetos de Aprendizagem nas escolas. Tal concepção tinha como linha de base a necessidade de incrementar diferentes trocas e interações entre os participantes através do desenvolvimento de novas funcionalidades (chats; fóruns) passíveis de incluir um tipo de comunicação todos-todos e não um-um, clássica nos modelos de educação a distância que se davam através de trocas de correspondência pelo correio convencional.

Retomando o primeiro ponto relacionado à política de formação interdisciplinar de pesquisadores, exposto no início desta seção, constatou-se que a composição interdisciplinar era de crucial importância não somente para a pesquisa, como também para constituir a equipe de formadores. As equipes de formação contaram, desde as primeiras experiências, com os pesquisadores do Laboratório de formação básica diversificada (psicólogos, engenheiros eletricistas, analistas de sistemas, matemáticos, linguistas, físicos, artistas plásticos). Aliado a essa diversidade, todos tinham como ponto de afinidade a informática educativa e trabalhavam de forma interdisciplinar nas pesquisas e experiências realizadas tanto no LEC, quanto em projetos conjuntos com outros setores da Universidade em projetos interinstitucionais. Como resultado da interação com essa equipe de formadores, que realizavam uma prática interdisciplinar, constatamos que os professores nas escolas públicas federais, estaduais e municipais, formaram núcleos de incubação e geração de experiências, também interdisciplinares que, gradativamente, transformam-se em polos irradiadores.

A apropriação da metodologia realizada pelos professores participantes dos cursos, fortaleceu a parceria interinstitucional com o LEC, seja no acompanhamento e assessoria às ações de multiplicação nas redes, seja no aperfeiçoamento do modelo de formação. Paralelamente à formação de professores para a implantação dos Núcleos de Tecnologia de várias regiões brasileiras, incluindo a norte e a nordeste, o LEC participou do Projeto Educação à Distância em 
Ciência e Tecnologia - EducaDI/CNPq ${ }^{3}$. A partir de demandas de educadores do Rio Grande do Sul, São Paulo, Brasília e Ceará, o projeto foi coordenado pelo Prof. Mauro Pequeno (IFCE) visando a aplicação de novas abordagens de uso das Tecnologias da Informação e da Comunicação (TIC) para trabalhar com alunos do Ensino Básico com defasagem idade/série de regiões urbanas marginais. Dentre as várias parcerias estabelecidas, destaca-se o Projeto piloto Amora ${ }^{4}$, realizado no Colégio de Aplicação da UFRGS, em Porto Alegre, o qual serviu de referência para a implementação do Projeto EducaDi. O projeto teve apoio do ambiente virtual TECLEC ${ }^{5}$ que foi desenvolvido no LEC, contando com recursos para promover a interação (fórum, ambiente para projetos, espaços para registro individual e de grupo). Com o apoio do TECLEC e de outros ambientes, como o TELEDUC, o LEC pode realizar experiências de formação que permitiram a consolidação de um modelo de formação, denominado de comunidades de aprendizagem. Os resultados obtidos no Projeto EducaDi/CNPq foram sintetizados no livro Aprendizes do futuro: as inovações começaram! ${ }^{6}$ (FAGUNDES, SATO E MAÇADA, 1998) propiciando o acesso sistematizado das concepções pedagógicas para a formação de professores e da participação ativa dos estudantes em seus processos de aprendizagem.

Em 1998-1999, o LEC deu continuidade à parceria com o Núcleo de Informática Aplicada à Educação (NIED/ UNICAMP) para o desenvolvimento do projeto de Formação de Professores a Distância via Rede Telemática. O projeto possibilitou desenvolver metodologias de intervenção e avaliação do processo de construção de conhecimento dos professores multiplicadores responsáveis pela implantação dos NTEs, visando a integração das modalidades de educação presencial e a distância, usando sistemas de Internet e teleconferências. Os resultados dessa parceria tornaram possível desenvolver um projeto multilateral com a participação de 16 países da América Latina e Caribe, além do Brasil. O desenvolvimento de metodologias e avaliação também foi acompanhado pelo desenvolvimento de produtos digitais. Nesse período, foram criados os ambientes virtuais de aprendizagem Sitecria, para facilitar a interação para aprendizagem ativa de alunos tendo por base a ideia de envolver professores e estudantes, no desenvolvimento de projetos compartilhados. A participação nessa comunidade virtual também criava a oportunidade para que os professores acompanhassem seus alunos no mesmo processo

3 Entre os anos de 1997 e 1998, desenvolveu a convite do Presidente do CNPq o Projeto Educação à Distância em Ciência e Tecnologia - EducaDI/CNPq.

$4 \quad$ Iniciado em 1995, o Projeto Amora tem produzido conhecimentos e metodologias com vistas à reestruturação curricular no Ensino Fundamental ao incorporar as Tecnologias da Informação e Comunicação. Realiza-se em parceria com professores do Colégio Aplicação de nossa Universidade. Seus resultados serviram e servem de inspiração para diferentes projetos, redesenhando o que a Profa. Lea cunhou como "Projetos de Aprendizagem", que se encontra publicado em dissertações, teses, livros e artigos.

5 Para dar suporte ao Projeto EducaDI/CNPq, foi desenvolvido um dos primeiros ambientes virtuais, o TECLEC que serviu de base para outros - AVAs (Ambientes Virtuais de Aprendizagem). Nele, o LEC idealizou o que viria a se constituir em um dos pilares dos AVAs atuais: a criação de ferramentas de interação todos-todos.

6 http://www.dominiopublico.gov.br/pesquisa/DetalheObraForm.do?select_action=\&co_obra=40249 
de aprendizagem cooperativa. Na área de matemática, foi criado o ambiente cooperativo

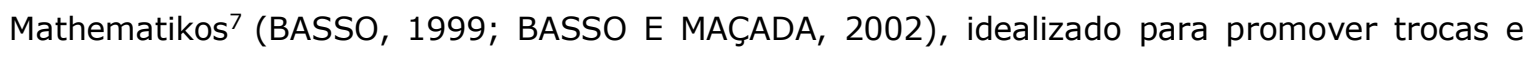
construção de conhecimento matemático entre professores e estudantes. Também nessa área, foram desenvolvidos os ambientes Mathema e Matematicão ${ }^{8}$, com produção de estudantes de Licenciatura em Matemática da UFRGS e utilizados por crianças e adolescentes em Escolas públicas. A lista de produtos tecnológicos, conforme é apresentado na Figura 1, inclui ainda ambientes de robótica educacional (Roboticando), chat de ciências (DR. Kaos), Educação

7 http://mathematikos.mat.ufrgs.br

8 http://matematicao.mat.ufrgs.br 
Ambiental (Parque das Águas), oficinas para uso de recursos web (ThoolLEC), estudos sobre ciências sócio-históricas (Sociedade e Cidadania), oficinas de Física e Matemática (FisiMat).

Figura 1 - Ambientes de Aprendizagem.
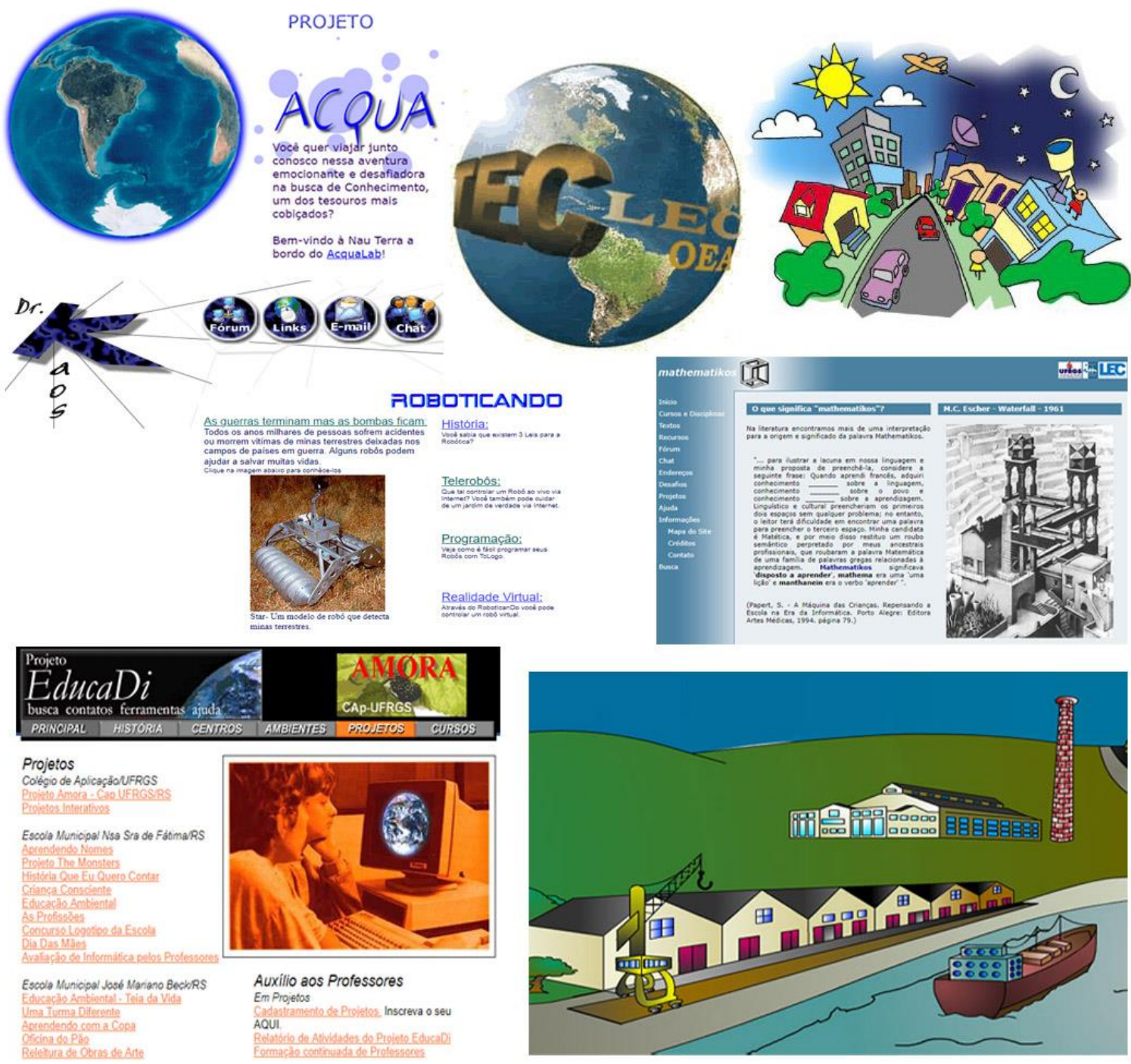

Fonte: LEC/UFRGS

A idealização de uma rede entre escolas, iniciada em 1991 via rádio amador, se expandiu na década seguinte e borrou as fronteiras entre educadores sul-americanos. O Projeto, Rede Telemática para Formação de Educadores (2001-2002), financiado pelo MEC/OEA, teve a participação de vários países como Argentina, Chile, Colômbia, Costa Rica, República Dominicana e Venezuela. Além dos professores, foram convocados os gestores das escolas com o intuito de propiciar condições para uma formação permanente e qualificada. As parcerias assim constituídas possibilitaram a criação do Centro Virtual Interamericano de Cooperação Solidária para Formação de Educadores (MEC/OEA), com o objetivo de divulgar propostas de formação de educadores via 
telemática, otimizar o intercâmbio sobre novas metodologias na formação profissional e as trocas de experiências socioculturais.

Após esse período, o LEC desenvolveu o Programa Escola, Conectividade, Sociedade da Informação e Conhecimento (ECSIC-2003/2004). O programa foi desenvolvido em parceria com a Prefeitura Municipal de Porto Alegre/Secretaria Municipal de Educação, com o financiamento do Banco Nacional de Desenvolvimento Social (BNDES). Cabe destacar sua dimensão formativa, seja no âmbito da UFRGS, que trabalhou com 90/145 bolsistas de graduação e pós-graduação, para garantir assistência e apoio às práticas docentes no âmbito da Escola Pública Municipal, seja na formação dos próprios professores das escolas para a disseminação de inovações curriculares, considerando as necessidades de transformação do modelo de Escola da Sociedade Industrial para um novo modelo: o da Escola que vai formar o cidadão da Sociedade da Informação e do Conhecimento. Intrinsecamente associado à proposta de formação do Projeto ECSIC, foi desenvolvido o ambiente virtual de aprendizagem Amadis (Projeto Amadis/FINEP) tendo como principal finalidade ser utilizado como ferramenta de apoio à Pedagogia de Projetos de Aprendizagem. A arquitetura do ambiente Amadis, sustentada nas pesquisas de campo desenvolvidas pelo LEC, incorporou elementos para favorecer a adaptação a diferentes situações de aprendizagem e a implementação de funcionalidades para apoiar a construção cooperativa do conhecimento.

Na continuidade das pesquisas e avaliação de práticas inovadoras para a inclusão da escola na cultura digital, o LEC participou, a partir de 2006, do Projeto UCA - Um Computador por Aluno do Ministério da Educação. As primeiras experiências sobre a inserção de laptops educacionais na sala de aula contemplaram o desenvolvimento de conteúdos digitais em mídias integradas e interativas para apoiar práticas pedagógicas inovadoras dos currículos em diferentes níveis de ensino para a aprendizagem dos alunos. O Projeto também gerou documentação sobre modalidades de formação de professores a distância em serviço usando os conteúdos digitais desenvolvidos.

O percurso exposto na seção anterior do texto possibilitou mapear projetos desenvolvidos no LEC envolvendo a formação de educadores. Cabe salientar que destacamos os projetos coletivos, deixando de comentar uma série de outros, mais individualizados, que foram objetos de teses e dissertações. Esse mapa permite indicar a importância do trabalho desenvolvido pelo Laboratório, não somente em nível nacional, mas também destacar as construções feitas neste percurso. Retomando as proposições iniciais da Profa. Léa Fagundes de que "Todos são capazes de aprender" e que "Um professor pode ensinar o que ainda não sabe, ao se dispor a aprender junto com seu aluno", podemos dizer que, em todo o percurso formativo, essas balizas estiveram presentes e foram ampliadas. As tecnologias digitais oportunizaram um movimento no qual professores e pesquisadores se colocaram em uma posição de aprendizes, tornando possível problematizar suas certezas em relação ao ensinar e ao aprender e construir novos modos de trabalhar juntos. Vimos isso quando os participantes dos cursos se apropriaram e utilizaram com seus alunos modos exploratórios, de justificação e de contra-argumentação de ideias e conhecimentos. Vimos isso ao trabalhar com diferentes formações iniciais de profissionais 
capazes de produzir afinidade com um objetivo comum. Vimos na capacidade de escuta da trajetória de pensamento e ação do outro e nos modos de buscar uma intervenção que impulsione o pensamento. Vimos ainda no momento em que vários professores em formação buscaram seguir pesquisando e incentivando colegas para formar coletivos de pesquisas em escolas.

\section{O LEC e seus frutos - uma disseminação criativa}

Feito esse breve mapa que pontua um percurso já longo, cabe ressaltar algumas proposições que, em nosso entender, tornaram esse trabalho possível. A primeira delas, é a de constituir e difundir uma prática interdisciplinar, tanto na formação de pesquisadores como na de professores. Prática baseada nos diferentes saberes, provenientes das formações iniciais e de experiências de vida e de trabalho, que se refazem ao convergir em um modo coletivo de ação. A segunda, o cultivo de uma posição de horizontalidade, na qual pesquisadores e professores buscam colocar-se lado a lado com pesquisados e estudantes, para compreender e desafiar suas trajetórias. A terceira, a de condição problematizadora da tecnologia digital. Muito antes de representar a solução de problemas educacionais, a aposta sempre foi a de como o acoplamento com as tecnologias digitais pudesse provocar novos questionamentos. Questionar modos habituais de pensar, de aprender; formas institucionais de ensinar; modos tradicionais de formar professores para deixar aberta a possibilidade de criação, de invenção. Nem sempre perseguir essas proposições significa um trabalho fácil. Ao contrário, faz-se necessário acompanhar o trabalho com uma autoanálise permanente.

Nós, autores deste texto, tivemos a vibrante possibilidade de participarmos, em diferentes momentos, com maior ou menor intensidade, desse coletivo de aprendizagem que é o Laboratório de Estudos Cognitivos da UFRGS. Diz-se da UFRGS pois não cabe na configuração de pertencimento somente a uma unidade da universidade. E, como vimos, pela importância de seu trabalho, poderia dizer-se do Brasil ou da América Latina. Falamos, nessa conclusão, no LEC no passado e no presente. No passado, pois nunca se instituiu de um modo identitário, sempre foi LEC-processo. Enquanto processo, as forças coletivas que o constituem o mantém em permanente reconfiguração. O LEC vive em muitas linhas de pesquisas espalhadas em programas de pós-graduação coordenadas por seus ex-integrantes. O LEC vive em muitos projetos de aprendizagem levados a efeito por professores que participaram de seus cursos. O LEC vive em muitas Escolas, Universidades, Instituições parceiras em seu percurso. O LEC vive no nosso encontro para a escrita deste capítulo. Trata-se de uma disseminação criativa, que segue existindo/insistindo em muitos coletivos interdisciplinares que de algum modo foram contaminados pelo LEC-processo. 


\section{Referências}

AXT, M. A Lógica da Programação com Linguagem Logo e a Teoria de Paulo Freire. In: AXT, M. (Org.). Os Micromundos Logo da Linguagem. 1ed.PORTO ALEGRE / RS: UFRGS - FUNTEVÊ, 1986, v. 1 , p. 11-16.

AXT, M. Explorando Listas em Logo. 1a. ed. SÃO PAULO / SP: McGraw-Hill, 1989.

AXT, M. Pensamento e Linguagem na Interação com Microcomputador; as Verbalizações Infantis como Instrumento de Diagnóstico de Dificuldades de Aprendizagem. Arquivos Brasileiros de Psicologia, Rio de Janeiro, v. 40, n.2, p. 3-23, 1988.

BASSO, M. V. A., FAGUNDES, L. C., TAROUCO, L. M. R., COSTA, A. C. R. Educação Tecnológica e/na Educação Matemática - Aplicações da Matemática Elementar na Sala de Aula Ou "Focinho de Porco Não é Tomada". Informática na Educação - Teoria e Prática. Revista do Curso de Pós Graduação em Informática na Educação - Universidade Federal do Rio Grande do Sul, outubro de 1999.

BASSO, M.V.A.; MAÇADA, D.L. Mathematikos: Dispuestos a Aprender. IN: MORAES, M.C. (Org.) Educação a distância: Fundamentos e práticas. Centro Virtual Interamericano de Cooperação Solidária para a Formação de Educadores. Organização dos Estados Americanos. NIED/UNICAMP, Campinas, $2002 . \quad$ Disponível em <http://www.nied.unicamp.br/oea/pub/livro3/espanhol/capitulo10.pdf>. Acesso em 27 maio 2018.

BIAZUS, M.C. Desenvolvimento Gráfico Plástico da Criança em Interação com o Computador. (Dissertação de Mestrado). Programa de Pós-Graduação em Psicologia, Universidade Federal do Rio Grande do Sul, Porto Alegre, 1991.

BÚRIGO, E. Z., BASSO, M. V. A.; A Construção de Conceitos Matemáticos por Crianças e Adolescentes. In: I Congresso Brasileiro de Psicopedagogia e III Encontro de Psicopedagogos. Associação Brasileira de Psicopedagogia. Seção SP/RS/RJ, São Paulo, 1988.

COSTA, I. E. T.; REAL, L. C. As Potencialidades de Crianças e Adolescentes Portadores de Necessidades Especiais Através da Interação com Micro-Computadores. In: José Armando Valente. (Org.). Liberando a mente: computadores na Educação Especial. Campinas: Gráfica Central da UNICAMP, 1991, v., p. 281-285.

COSTA, I. T; FAGUNDES, L. C; NEVADO, R. A. Projeto TecLec- Modelo de uma Nova Metodologia em EAD incorporando os Recursos da Telemática. In: Informática na Educação- Teoria e Prática. Porto Alegre, 1998. v.1 n.1.p.83-100.

FAGUNDES, L., SATO, L.S., MAÇADA, D.L. Aprendizes do Futuro: as inovações começaram! Brasília: Ministério da Educação. Secretaria Especial de Educação a Distância. 1999. Disponível em

<http://www.dominiopublico.gov.br/pesquisa/DetalheObraForm.do?select_action=\&co_obra=4 0249>. Acesso em 26 maio 2018.

FAGUNDES, L.C.; NEVADO, R.A, BASSO, M. V. A.; MENEZES, C.S.; BITTENCOURT, J.; MONTEIRO, V. C. P. C. Projetos de Aprendizagem - Uma experiência mediada por ambientes telemáticos. Revista Brasileira de Informática na Educação, Porto Alegre - RS, v. 14, n.1, p. 2939, 2006.

FAGUNDES, L.C. Psicogênese das Condutas Cognitivas da Criança em Interação com o Mundo do Computador, (Tese de Doutorado) Universidade de São Paulo, USP, Brasil. 1986.

KESSLER, C.H. Problemas de Aprendizagem: cognição ou afeto? (Dissertação de Mestrado). Programa de Pós-Graduação em Psicologia, Universidade Federal do Rio Grande do Sul, Porto Alegre, 1991.

MARASCHIN, C. A criança pré-escolar e a linguagem logo. Psicologia. Reflexão e Crítica, v. 5, n.1, p. 85-100, 1992. 
MARASCHIN, C. Ambiente logo e alfabetização. Psicologia. Reflexão e Crítica, v. 5, n.1, p. 123$130,1992$.

MARASCHIN, C. Os processos de leitura e de escrita de crianças em interação com o computador. Arquivos Brasileiros de Psicologia, Fundação Getúlio Vargas, v. 41, n.1, p. 3-11, 1989.

MARASCHIN, C. Palavras mágicas. Educação e Realidade, v. 18, n.1, p. 71-80, 1993.

MARASCHIN, C. Processos cognitivos envolvidos na atividade de programação de crianças de 4 a 6 anos com a linguagem logo de programação. (Dissertação de Mestrado). Programa de PósGraduação em Psicologia, Universidade Federal do Rio Grande do Sul, Porto Alegre, 1986.

MARASCHIN, C.; FAGUNDES, L. A Linguagem logo como instrumento terapêutico das dificuldades de aprendizagem: possibilidades e limites. Psicologia. Reflexão e Crítica, v. 5, n.1, p. 19-28, 1992.

MARASCHIN, C.; FAGUNDES, L. Em busca de novos recursos para a alfabetização. Psicologia. Reflexão e Crítica, v. 5, n.1, p. 29-42, 1992.

MARASCHIN, C.; NEVADO, R. A. Ambientes de de aprendizagem informatizados e alfabetização. Revista de Estudos, v. 4, n.1, p. 85-87, 1991.

MARASCHIN, C.; NEVADO, R. A. O desenvolvimento cognitivo de crianças com necessidades especiais em interação com o ambiente logo. Psicologia. Reflexão e Crítica, v. 5, n.1, p. 101-122, 1992.

NEVADO, R. A.; COSTA, I.; FAGUNDES, L.C. Projeto TEC-LEC: Modelo de uma nova metodologia em EAD incorporando os recursos da telemática. Revista Informática na Educação Teoria e Prática, PGIE/UFRGS- Porto Alegre, v. 1, n.1, p. 83-100, 1998.

NEVADO, R. A.; FAGUNDES, L.C., BASSO, M.V.A. Escola, Conectividade e Sociedade da Informação um Programa em Andamento. Como Disseminar Novos Modelos de Uso das Tecnologias Digitais para a Melhoria da Qualidade da Aprendizagem dos Alunos na Rede Pública de Ensino? In: XXI Seminário de Extensão do Rio Grande do Sul, 2003, Gramado. Anais do XXI SEURS, 2003.

NEVADO, R.A. As Abstrações na Construção da Língua Escrita e do Espaço Métrico na Interação com o Computador, durante o Processo de Alfabetização. (Dissertação de Mestrado). Programa de Pós-Graduação em Educação, Universidade Federal do Rio Grande do Sul, Porto Alegre, 1989.

PEDÓ, M. A Legalidade no Ambiente Logo. (Dissertação de Mestrado). Programa de PósGraduação em Psicologia, Universidade Federal do Rio Grande do Sul, Porto Alegre, 1992.

PETRY, P. P.; FAGUNDES, L. C. O preparo de professores para trabalhar no ambiente LOGO. Psicologia. Reflexão e Crítica, Porto Alegre, v. 5, n.1, p. 11-17, 1992.

Recebido em julho de 2019.

Aaprovado para publicação em setembro de 2019.

\section{Léa da Cruz Fagundes}

Professora titular aposentada do Departamento de Psicologia Social e Institucional/UFRGS. Foi docente e orientadora nos Programas de Pós-Graduação em Psicologia Social e Institucional e no de Informática na Educação/UFRGS. Fundou e foi coordenadora do Laboratório de Estudos Cognitivos (LEC/UFRGS) e assessora do Ministério de Educação, leafagundes@gmail.com

\section{Rosane Aragón}

Professora Titular da Faculdade de Educação da UFRGS. Docente e orientadora no Programa de Pós-

Graduação em Educação da UFRGS. Coordenadora do Curso de Graduação em Pedagogia - Licenciatura na 
modalidade a distância (PEAD/FACED/UFRGS) de 2005-2011. Coordenadora Adjunta do Centro de Professores da UFRGS (FORPROF/UFRGS), rosane.aragon@gmail.com

\section{Marcus Vinicius de Azevedo Basso}

Professor titular do Instituto de Matemática e Estatística da UFRGS. Docente e orientador nos Programas de Pós-graduação em Ensino de Matemática e Informática na Educação da UFRGS. Atualmente coordena o Centro de Formação Continuada de Professores (FORPROF) da UFRGS e o Programa de Pós-graduação em Ensino de Matemática, mbasso@ufrgs.br

\section{Cleci Maraschin}

Professora titular aposentada do Departamento de Psicologia Social e Institucional/UFRGS. Professora colaboradora convidada nos Programas de Pós-Graduação em Informática na Educação e em Psicologia Social e Institucional da UFRGS, cleci.maraschin@gmail.com 